\title{
Thermal Loads Effect on Response of One- Story Reinforced Concrete Frame Buildings in UAE
}

\author{
Sabouni Reem ${ }^{1, *}$, and Sydnaoui Ikhlass $^{2}$ \\ ${ }^{1}$ Civil Engineering Department Chair, Civil Engineering Department. ALHOSN University, Abu \\ Dhabi, UAE \\ ${ }^{2}$ Structural Engineer, Musanada, Abu Dhabi General Services Company, Abu Dhabi, UAE
}

\begin{abstract}
In this paper the effect of temperature change (thermal load) on one-story reinforced concrete frame buildings allocated in the UAE is studied. Sixty eight finite element models with different story heights and slab lengths were developed in ETABS to carry out this study. The effect of temperature change with the variation of story height, slab length and support condition on the lateral displacement and horizontal reactions was studied in this paper. The thermal load results for the fixed support models showed that for different buildings with the same column heights, the external columns' displacements and reactions increased considerably with increasing the slab length. Comparing the horizontal reaction results -due to thermal loads- of the two modeled building heights $(3 \mathrm{~m}$ and $6 \mathrm{~m}$ ) showed that the $6 \mathrm{~m}$ models have lower reactions at external columns but larger top displacements. The comparison between the lateral load results for fixed and hinged support conditions showed that models with fixed support conditions had lower lateral displacement but higher horizontal reactions due to thermal loads. The effect of the support condition on the lateral displacement was larger for longer slab lengths whereas its effect on the horizontal reaction was larger for smaller slab lengths. The support conditions showed to have larger effect on the shorter column models.
\end{abstract}

\section{Introduction}

The UAE is known for its high temperatures especially during the summer period. This high temperature along with the frequent fluctuation in the daily and seasonal temperatures imposes extra loads on structures. The Abu Dhabi International Building Code (2013) (ADIBC) considers temperature loads as one of the main important loads to be verified and analyzed in reinforced concrete structures in the UAE [1]. Seasonal changes in temperature causes overall structural deformation, displacements, in addition to differential stresses in concrete elements. It has to be considered for building serviceability conditions and to eliminate the additional thermal cracks [2]. When studying the effect of temperature change

\footnotetext{
* Corresponding author: r.arsabouni@alhosnu.ae
} 
on reinforced concrete buildings two important factors should be considered: the nature of the temperature change and the fundamental materials properties of concrete.

In service, thermal effects are related to the difference between the highest temperature during summer and the lowest temperature during winter [2]. The highest temperature registered in the UAE was found to be $50^{\circ} \mathrm{C}$ (in the western region); whereas the lowest registered temperature was found to be $10^{\circ} \mathrm{C}$. The magnitude of the forces developed and the amount of displacements caused by temperature changes are directly related to building length [2]. Contraction and expansion joints are means used to limit the magnitude of forces, displacements and cracking induced by temperature [3]. A common practice in the UAE is that expansion joints spacing shouldn't be more than $120 \mathrm{ft}(36.6 \mathrm{~m})$ considering recognized committees recommendations $[1,2,4]$, when the spacing exceeds $450 \mathrm{ft}(46 \mathrm{~m})$, then a special design including a thermal study has to be performed $[2,5]$.

\section{ETABS models input data and conditions}

\subsection{Concrete properties}

The thermal coefficient of concrete is usually affected by many factors such as the type of aggregate, moisture content, mix properties, cement type and age of concrete. For ordinary thermal stresses calculations a thermal coefficient value of $10 \times 10-61^{\circ} \mathrm{C}$ can be used when the type of aggregate and concrete degree of saturation are unknown [2,6]. Accordingly this value was implemented in the used ETABS models (Fig. 1). The rest of the concrete properties are presented in Table 1.

Table 1. Concrete properties used in the model.

\begin{tabular}{|c|c|}
\hline Concrete Property & Value \\
\hline Concrete compressive strength $\left(f c^{\prime}\right)$ & $40 \mathrm{~N} / \mathrm{mm}^{2}$ \\
\hline Modulus of elasticity $(E)$ & $30000 \mathrm{MPa}$ \\
\hline Poisson ratio & 0.2 \\
\hline Mass per unit volume & $2400 \mathrm{~kg} / \mathrm{m}^{3}$ \\
\hline
\end{tabular}
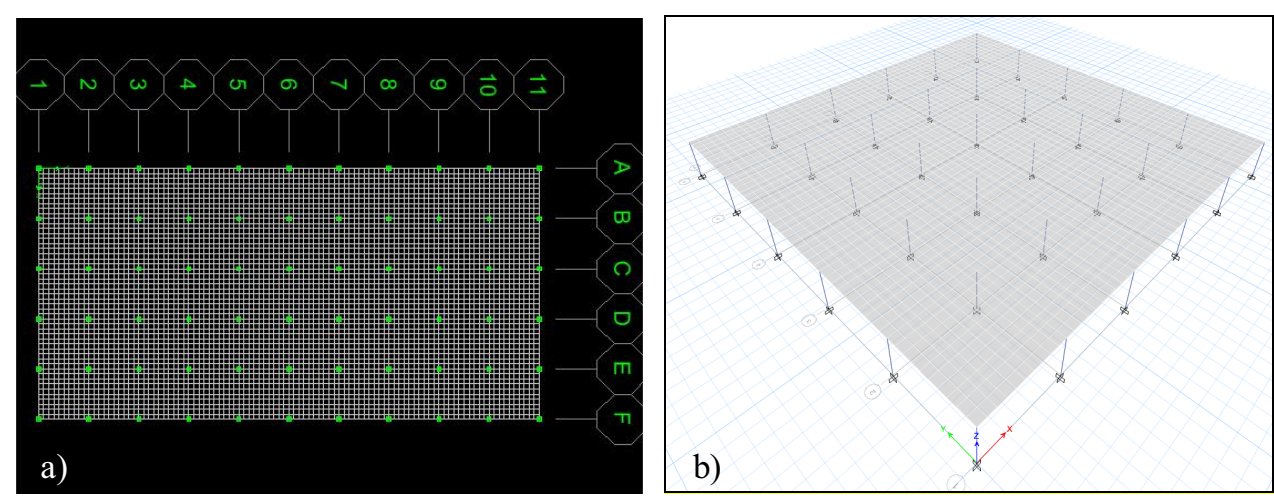

Fig. 1. Typical model: a) Top view slab and b) 3D view.

\subsection{ETABS model geometry}

Sixty eight ETABS one-story reinforce concrete frame building models were generated in this study (Fig. 1). These models were divided into two sets: fixed support reaction and 
hinged support reaction and each set consists of two model groups: the first group with column heights of $3.00 \mathrm{~m}$ and the second group with column heights of $6 \mathrm{~m}$. Each group consists of 17 different ETABS models. The difference between these models is the concrete slab length which was increased from $50 \mathrm{~m}$ to $400 \mathrm{~m}$ by increments of $10 \mathrm{~m}$. These models were generated to verify the effect of temperature change with variation in column height, slab length and support conditions on the lateral displacement and horizontal reactions in one-story reinforced concrete frame buildings in UAE. The rest of the model geometry was taken as follows:

i) Slab thickness $=300 \mathrm{~mm}$

ii) Columns size $=800 \times 800 \mathrm{~mm}^{2}$

iii) Thermal load $=40^{\circ} \mathrm{C}$

iv) Slab width $=50 \mathrm{~m}$.

Thermal loads $\left(40 \mathrm{C}^{\circ}\right)$ were assigned as uniform temperature change at all slab shells elements at upper slab level.

\section{Results and analysis}

In this section the results of the thermal study conducted on the sixty eight reinforced concrete frame structure models are presented. The results from the first set of models with fixed support conditions were used to study the effect of temperature change with variation in column height and slab length on the lateral displacement and horizontal reactions in one-story reinforced concrete frame buildings in UAE. The results from the second set of models with hinged support conditions were compared to the results of the first set of models to study the influence of the support conditions on the temperature change results.

\subsection{Effect of thermal load}

For the first set of models (with fixed support) the change in the horizontal reactions and the top deflection at the external columns A1, B1, C1, D1, E1 and F1 with different slab lengths under thermal load are shown in Fig. 2 and Fig. 3 for the $3 \mathrm{~m}$ and $6 \mathrm{~m}$ high structures, respectively. Due to symmetry in the analyzed models these columns will have the same results as those for columns A11, B11, C11, D11, E11 and F11, respectively. All models were found to be safe under dead and live loads.

These thermal load results show that for the same building the displacements at external columns have different but close values. The results also show that for different buildings with the same column heights, the external columns' displacements increases considerably with increasing the slab length. The external column displacements for $400 \mathrm{~m}$ slab was about three times that for the $50 \mathrm{~m}$ slab length for the $3 \mathrm{~m}$ high column models and about five times for that in the $6 \mathrm{~m}$ high column modes. The maximum allowable lateral deflection in columns is (height/180) to avoid damage to external walls [3]. This limit is $16.7 \mathrm{~mm}$ and $33.3 \mathrm{~mm}$ for the $3 \mathrm{~m}$ and $6 \mathrm{~m}$ high columns, respectively. The model results showed that this limit was exceeded for slabs with length more than $100 \mathrm{~m}$ for the $3 \mathrm{~m}$ high column models and for slabs with length more than $200 \mathrm{~m}$ for those of the $6 \mathrm{~m}$ high column models.

For the same building (in the first model set) the thermal load results showed that the horizontal reactions (parallel to the slab length) at external columns' supports have different but close values. For different buildings with the same column height, the external columns reactions at supports increased considerably with the increase of the slab length. This has a big impact on these columns and its related footing design. The study results showed that the reactions for the $400 \mathrm{~m}$ long slab was about three times that for $50 \mathrm{~m}$ long slab for the 3 $\mathrm{m}$ high column models and about nine times for the $6 \mathrm{~m}$ high column models. Comparing 
the results of the two modeled building heights $(3 \mathrm{~m}$ and $6 \mathrm{~m})$ show that the $6 \mathrm{~m}$ models have lower reactions at external columns but larger top displacements due to the thermal loading.

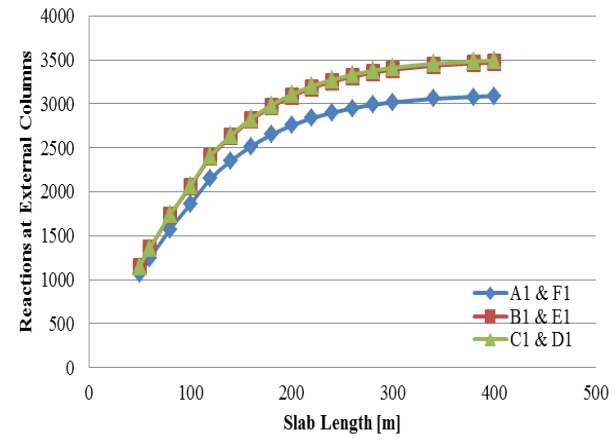

(a)

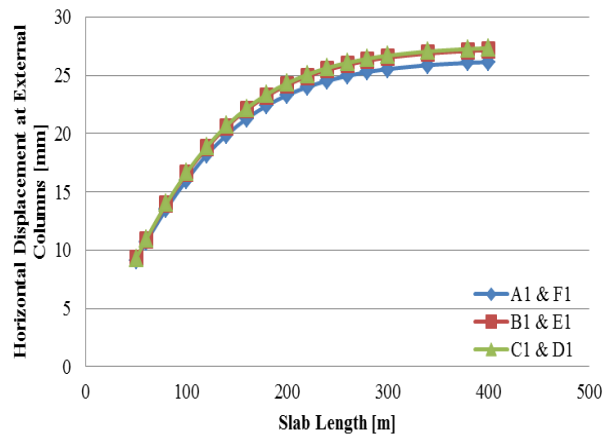

(b)

Fig. 2. Results of thermal study at external columns for $3 \mathrm{~m}$ height models and different slab length: a) Reaction and b) Horizontal displacement.

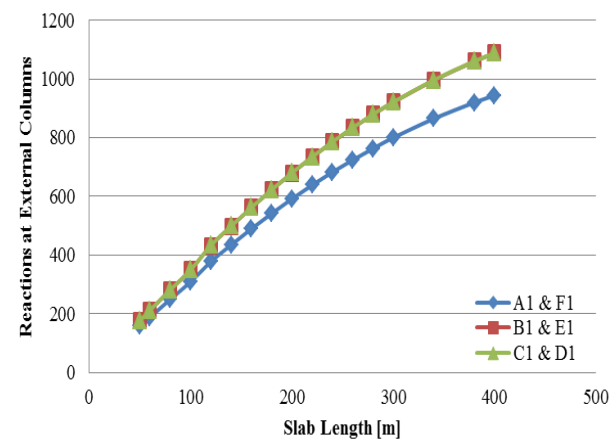

(a)

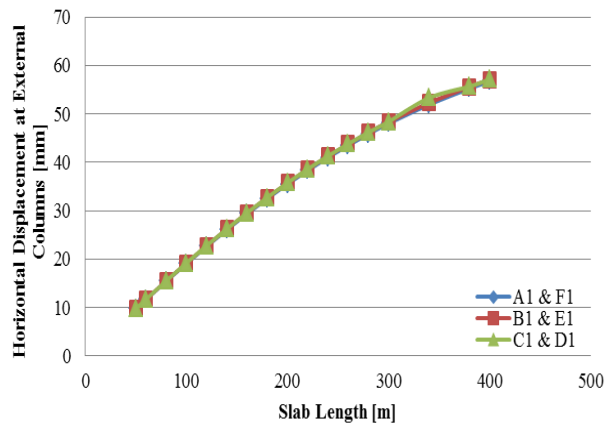

(b)

Fig. 3. Results of thermal study at external columns for $6 \mathrm{~m}$ height models and different slab length: a) Reaction and b) Lateral displacement.

\subsection{Effect of support conditions on the thermal response}

To study the effect of support type on the displacement and reactions of external columns under thermal load a second set of thirty four new models were created. This set of models had the same properties as the first set of models except that the second set had hinged support condition instead of fixed support condition. The displacements under thermal load results for both sets of models are shown in Table 2 and Table 3 for models with column heights $(3 \mathrm{~m})$ and $(6 \mathrm{~m})$, respectively. The comparison between the results of both sets of models showed that the displacement for the models with hinged support had higher values than that for the fixed support. This increase in the value of displacement increased with the increase of the slab length for each column height. When comparing the results for the $3 \mathrm{~m}$ high columns models and the $6 \mathrm{~m}$ high column models it was found that the support condition had a larger effect on the shorter column length. The ratio of the lateral displacement for the fixed support condition to the hinged support condition for the $6 \mathrm{~m}$ column height is larger than $75 \%$ for all slab lengths. For the $3 \mathrm{~m}$ high column models the 
ratio of the lateral displacement for the fixed support conditions to the hinged support condition for slab lengths lesser than $160 \mathrm{~m}$ were more than $75 \%$. This ratio decreases with the increase of the slab length with a reduction reaching $45 \%$ for slab length of $400 \mathrm{~m}$.

Table 2. Lateral deformation for column height $(3 \mathrm{~m})$ with fixed and hinged supports.

\begin{tabular}{|c|c|c|c|c|c|c|}
\hline $\begin{array}{c}\text { Slab } \\
\text { Length } \\
(\mathbf{m})\end{array}$ & \multicolumn{3}{|c|}{ Fixed columns conditions } & \multicolumn{3}{c|}{ Hinged columns conditions } \\
\hline & A1 \& F1 [mm] & B1 \& E1 [mm] & C1 \& D1 [mm] & A1 \& F1 [mm] & B1 \& E1 [mm] & C1 \& D1 [mm] \\
\hline 50 & 9.1397 & 9.258 & 9.2946 & 9.8593 & 9.8544 & 9.8559 \\
\hline 60 & 10.6902 & 10.9077 & 10.9556 & 11.8096 & 11.8055 & 11.8065 \\
\hline 80 & 13.5291 & 13.9285 & 13.998 & 15.6769 & 15.674 & 15.6736 \\
\hline 100 & 15.9955 & 16.5529 & 16.6606 & 19.4882 & 19.4863 & 19.4845 \\
\hline 120 & 18.1666 & 18.7634 & 18.8693 & 23.1548 & 23.1542 & 23.1516 \\
\hline 140 & 19.8894 & 20.5792 & 20.6982 & 26.7737 & 26.7737 & 26.7699 \\
\hline 160 & 21.2884 & 22.0537 & 22.1834 & 30.2894 & 30.286 & 30.2849 \\
\hline 180 & 22.4085 & 23.2343 & 23.3726 & 33.6918 & 33.693 & 33.6867 \\
\hline 200 & 23.2953 & 24.169 & 24.314 & 36.9725 & 36.9742 & 36.9668 \\
\hline 220 & 23.9912 & 24.9024 & 25.0528 & 40.1246 & 40.127 & 40.1184 \\
\hline 240 & 24.5334 & 25.4739 & 25.6284 & 43.143 & 43.1459 & 43.1363 \\
\hline 260 & 24.9536 & 25.9167 & 26.0744 & 46.0239 & 46.0273 & 46.0166 \\
\hline 280 & 25.2778 & 26.2585 & 26.4186 & 48.765 & 48.7688 & 48.7572 \\
\hline 300 & 25.5271 & 26.5213 & 26.6833 & 51.3654 & 51.3696 & 51.3571 \\
\hline 340 & 25.8649 & 26.8773 & 27.0419 & 56.1462 & 56.1513 & 56.1371 \\
\hline 380 & 26.0624 & 27.0855 & 27.2516 & 60.3813 & 60.3872 & 60.3715 \\
\hline 400 & 26.1277 & 27.1543 & 27.3209 & 62.3026 & 62.3088 & 62.2924 \\
\hline
\end{tabular}

Table 3. Lateral deformation for column height $(6 \mathrm{~m})$ with fixed and hinged supports.

\begin{tabular}{|c|c|c|c|c|c|c|}
\hline $\begin{array}{c}\text { Slab } \\
\text { Length } \\
(\mathbf{m})\end{array}$ & \multicolumn{3}{|c|}{ Fixed columns conditions } & \multicolumn{3}{c|}{ Hinged columns conditions } \\
\hline & A1 \& F1 [mm] & B1 \& E1 [mm] & C1 \& D1 [mm] & A1 \& F1 [mm] & B1 \& E1 [mm] & C1 \& D1 [mm] \\
\hline 50 & 9.7842 & 9.8001 & 9.8057 & 9.9 & 9.9 & 9.9 \\
\hline 60 & 11.691 & 11.7247 & 11.7324 & 11.9 & 11.9 & 11.9 \\
\hline 80 & 15.4494 & 15.5183 & 15.5299 & 15.8 & 15.8 & 15.8 \\
\hline 100 & 19.1189 & 19.2221 & 19.2375 & 19.7 & 19.7 & 19.7 \\
\hline 120 & 22.6826 & 22.7991 & 22.8186 & 23.6 & 23.6 & 23.6 \\
\hline 140 & 26.1135 & 26.2569 & 26.2801 & 27.5 & 27.5 & 27.5 \\
\hline 160 & 29.4063 & 29.5755 & 29.6022 & 31.4 & 31.4 & 31.4 \\
\hline 180 & 32.5508 & 32.7447 & 32.7747 & 35.2 & 35.2 & 35.2 \\
\hline 200 & 35.5395 & 35.7569 & 35.79 & 39 & 39 & 39 \\
\hline 220 & 38.3674 & 38.607 & 38.6431 & 42.7 & 42.7 & 42.7 \\
\hline 240 & 41.0318 & 41.2923 & 41.3312 & 46.5 & 46.5 & 46.5 \\
\hline 260 & 43.532 & 43.8121 & 43.8538 & 50.1 & 50.2 & 50.1 \\
\hline 280 & 45.8694 & 46.1679 & 46.212 & 53.8 & 53.8 & 53.8 \\
\hline 300 & 48.047 & 48.3625 & 48.4089 & 57.4 & 57.4 & 57.4 \\
\hline 340 & 51.9406 & 52.2867 & 52.3373 & 64.4 & 64.4 & 64.4 \\
\hline 380 & 55.2592 & 55.6313 & 55.6854 & 71.2 & 71.3 & 71.2 \\
\hline 400 & 56.7203 & 57.1039 & 57.1595 & 74.6 & 74.6 & 74.6 \\
\hline
\end{tabular}

The horizontal reaction under thermal load results for both sets of models are shown in Table 4 and Table 5 for models with column heights $(3 \mathrm{~m})$ and $(6 \mathrm{~m})$, respectively. The comparison between the horizontal reaction results of both sets of models showed that the reaction for the models with hinged support had lower values than that for the fixed 
support. The effect of support condition was larger on models with smaller slab lengths for both column heights. The column height was found to be inversely proportional to horizontal reaction values. It is clear that models with $3 \mathrm{~m}$ story height and fixed columns supports have the most critical reaction values. Horizontal reaction related to column height $3 \mathrm{~m}$ is three to five times bigger than reactions related to columns with height $6 \mathrm{~m}$. Fixed columns reactions for models with $3 \mathrm{~m}$ column height are around 15 times the hinged column reaction for model with $3 \mathrm{~m}$ column height and slab length $50 \mathrm{~m}$. This ratio decreased for models with longer slabs where, this ratio is around 6 for models with slab length of $400 \mathrm{~m}$.

Table 4. Horizontal reactions for column height $(3 \mathrm{~m})$ with fixed and hinged supports.

\begin{tabular}{|c|c|c|c|c|c|c|}
\hline $\begin{array}{c}\text { Slab Length } \\
(\mathbf{m})\end{array}$ & \multicolumn{3}{|c|}{ Fixed columns conditions } & \multicolumn{3}{c|}{ Hinged columns conditions } \\
\hline & A1 \& F1 [kN] & B1 \& E1 [kN] & C1 \& D1 [kN] & A1 \& F1 [kN] & B1 \& E1 [kN] & C1 \& D1 [kN] \\
\hline 50 & 1060.24 & 1146.31 & 1151.28 & 37.38 & 74.31 & 74.56 \\
\hline 60 & 1240.91 & 1352.62 & 1358.96 & 45.19 & 90.16 & 90.36 \\
\hline 80 & 1571.72 & 1730.42 & 1739.33 & 60.68 & 121.58 & 121.68 \\
\hline 100 & 1859.13 & 2058.64 & 2069.73 & 75.95 & 152.55 & 152.55 \\
\hline 120 & 2147.02 & 2393.91 & 2408.15 & 111.88 & 217.19 & 217.41 \\
\hline 140 & 2351.02 & 2627.11 & 2642.98 & 129.61 & 252.36 & 252.49 \\
\hline 160 & 2516.67 & 2816.47 & 2833.66 & 146.83 & 286.52 & 286.56 \\
\hline 180 & 2649.3 & 2968.09 & 2986.34 & 163.5 & 319.58 & 319.54 \\
\hline 200 & 2754.31 & 3088.13 & 3107.21 & 179.57 & 351.46 & 351.33 \\
\hline 220 & 2836.7 & 3182.32 & 3202.06 & 195.01 & 382.09 & 381.88 \\
\hline 240 & 2900.9 & 3255.71 & 3275.96 & 209.8 & 411.42 & 41.14 \\
\hline 260 & 2950.65 & 3312.58 & 3333.23 & 223.91 & 439.41 & 439.06 \\
\hline 280 & 2989.04 & 3356.46 & 3377.42 & 237.34 & 466.05 & 465.63 \\
\hline 300 & 3018.56 & 3390.22 & 3411.41 & 250.08 & 491.31 & 490.83 \\
\hline 340 & 3058.56 & 3435.94 & 3457.45 & 273.5 & 537.77 & 537.17 \\
\hline 380 & 3081.95 & 3462.67 & 3484.38 & 294.24 & 578.92 & 578.21 \\
\hline 400 & 3089.68 & 3471.51 & 3493.27 & 303.66 & 597.59 & 596.83 \\
\hline
\end{tabular}

Table 5. Horizontal reactions for column height $(6 \mathrm{~m})$ with fixed and hinged supports.

\begin{tabular}{|c|c|c|c|c|c|c|}
\hline Slab Length (m) & \multicolumn{3}{|c|}{ Fixed columns conditions } & \multicolumn{3}{c|}{ Hinged columns conditions } \\
\hline & A1 \& F1 [kN] & B1 \& E1 [kN] & $\begin{array}{c}\text { C1 \& D1 } \\
{[\mathbf{k N}]}\end{array}$ & A1 \& F1 [kN] & B1 \& E1 [kN] & $\begin{array}{c}\text { C1 \& D1 } \\
{[\mathbf{k N}]}\end{array}$ \\
\hline 50 & 157.36 & 176.65 & 176.92 & 9.05 & 17.38 & 17.47 \\
\hline 60 & 188.25 & 211.92 & 212.2 & 10.95 & 21.1 & 21.17 \\
\hline 80 & 249.12 & 281.43 & 281.73 & 14.75 & 28.52 & 28.57 \\
\hline 100 & 308.56 & 349.29 & 349.61 & 18.53 & 35.91 & 35.94 \\
\hline 120 & 377.2 & 432.08 & 432.63 & 27.25 & 50.82 & 50.91 \\
\hline 140 & 434.38 & 498.2 & 498.78 & 31.78 & 59.44 & 59.51 \\
\hline 160 & 489.25 & 561.66 & 562.26 & 36.28 & 68.01 & 68.05 \\
\hline 180 & 541.65 & 622.26 & 622.89 & 40.75 & 76.51 & 76.53 \\
\hline 200 & 591.46 & 679.86 & 680.52 & 45.18 & 84.94 & 84.94 \\
\hline 220 & 638.58 & 734.36 & 735.04 & 49.57 & 93.3 & 93.27 \\
\hline 240 & 682.98 & 785.71 & 786.41 & 53.91 & 101.57 & 101.52 \\
\hline 260 & 724.65 & 833.9 & 834.61 & 58.21 & 109.75 & 109.68 \\
\hline 280 & 763.6 & 878.94 & 879.68 & 62.46 & 117.83 & 117.74 \\
\hline 300 & 799.89 & 920.91 & 921.66 & 66.65 & 125.81 & 125.7 \\
\hline 340 & 864.78 & 995.95 & 996.74 & 74.87 & 141.45 & 141.29 \\
\hline 380 & 920.08 & 1059.9 & 1060.72 & 82.84 & 156.62 & 156.42 \\
\hline 400 & 944.43 & 1088.06 & 1088.89 & 86.73 & 164.01 & 163.8 \\
\hline
\end{tabular}




\section{Conclusions}

Throughout this research, sixty eight ETABS models of one-story reinforced concrete frame buildings were studied under thermal load from UAE registered values. These models were divided into two sets: fixed support reaction and hinged support reaction and each set consists of two model groups: the first group with column heights of $3 \mathrm{~m}$ and the second group with column heights of $6 \mathrm{~m}$. Each group consists of 17 different ETABS models. The difference between these models is the concrete slab length which was increased from $50 \mathrm{~m}$ to $400 \mathrm{~m}$ by increments of $10 \mathrm{~m}$. The findings of this research confirmed the considerable additional lateral deformations at slab level and horizontal forces at supports due to temperature loads. These deformations and reactions increases considerably with increasing the slab length. For a fixed support condition the horizontal displacements for $400 \mathrm{~m}$ slab was about three times that for the $50 \mathrm{~m}$ slab length for the 3 $\mathrm{m}$ high column models and about five times for that in the $6 \mathrm{~m}$ high column modes. Whereas, the reactions for the $400 \mathrm{~m}$ long slab was about three times that for $50 \mathrm{~m}$ long slab for the $3 \mathrm{~m}$ high column models and about nine times for the $6 \mathrm{~m}$ high column models.

When comparing the thermal loads results of both fixed and hinged support conditions, the displacement for the models with hinged support condition had higher values than that for the fixed support condition. The ratios of the lateral displacement under thermal loads for the fixed support condition to the hinged support condition for all the $6 \mathrm{~m}$ column height models and $3 \mathrm{~m}$ column height models with slab lengths lesser than $160 \mathrm{~m}$ were larger than $75 \%$. This ratio decreases with the increase of the slab length for the $3 \mathrm{~m}$ column height models with a reduction reaching $45 \%$ for slab length of $400 \mathrm{~m}$. The comparison between the horizontal reaction results of both sets of models showed that the reaction for the models with hinged support had lower values than that for the fixed support. The effect of support condition was larger on models with smaller slab lengths and shorter column heights. Horizontal reaction related to column height $3 \mathrm{~m}$ is three to five times bigger than reactions related to columns with height $6 \mathrm{~m}$. Fixed columns reactions for models with $3 \mathrm{~m}$ height are around 15 times the hinged column reaction for model with $3 \mathrm{~m}$ column height and slab length $50 \mathrm{~m}$. This ratio will be decreased for models with longer slabs where, this ratio will be around 6 for models with slab length of $400 \mathrm{~m}$.

\section{References}

[1] ADIBC 2013, Abu Dhabi international building code, 1, The Higher Building Code Committee Abu Dhabi, United Arab Emirates, (2013)

[2] ACI Committee 224, Joints in concrete construction, 3, ACI, US, (2001)

[3] ACI Committee 209, Prediction of creep, shrinkage, and temperature effects in concrete structures, 1, ACI, US, (1997)

[4] SCSE Committee, Expansion joints in buildings, 65, National Academy of Sciences, Washington, D.C., US, (2000)

[5] ACI Committee 330, Guide for design and construction of concrete parking lots, 1, ACI, US, (1997)

[6] The International Federation for Structural Concrete (Federation international du beton, fib), fib Model Code for Concrete Structures 2010, 1, Wiley, Germany, (2010) 